\title{
Depressive Symptoms \& Associated Stressors among Medical Students
}

\author{
Firas A. Al-Kadhimi* \\ Nesif J. Al-Hemiary** \\ Ahmed Hassan***
}

\author{
CABMS \\ FIBMS \\ FIBMS
}

Fac Med Baghdad 2017; Vol.59, No.3 Received: May 2017 Accepted: Oct. 2017
Background: Depressive symptoms are commonly occurring in many psychiatric illnesses. Many people experience the first symptoms of depression during their college years. Unfortunately, many college students who have depression are not getting the help they need.

Objectives : to find out the point prevalence of clinically significant depressive symptoms in students of Baghdad College of Medicine, University of Baghdad, and its association with life stressors.

Subjects and Methods: A cross sectional study of students of Baghdad College of Medicine, University of Baghdad during March and April 2013. A random sample was chosen and each student was asked to fill a questionnaire that contains demographic information, the Patient Health Questionnaire-9 (PHQ-9), Beck Depression Inventory-II (BDI-II), and the Student's Stressors Questionnaire. Data were analyzed by using SPSS (V.18). Appropriate tests were used for significance.

Results: A total of 250 students (140 females and 110 males) was surveyed which included 50 students from each year. Female to male ratio was 1.27. Their age ranged between $18-45$ years and the mean age was $22.2 \pm 2.3$. Twenty-eight percent have clinically significant depressive symptoms, $12.4 \%$ have milder form of depression according to PHQ-9. Clinical depressive symptoms found among $37.2 \%$ (borderline clinical depression to extremely severe depression) according to BDI-II. The mean of life stressors scores was 97.98 out of 180 ( $\mathrm{SD}=18.68)$. Educational, psychological, and environmental stressors were the most common types of stressors. There is strong statistical relationship between life stressor category and clinically significant depressive symptom $(\mathrm{P}$ value $=0.000)$.

Conclusion: clinically significant depressive symptoms are common among medical students of Baghdad University. Stressors were high and are positively associated with the presence of depressive symptoms.

Keywords: depressive symptoms, stressors, medical students

\section{Introduction:}

Depressive disorders are commonly occurring disorders in all countries. A cross-national comparison of major depression from 10 populationbased surveys show that lifetime prevalence estimates of major depressive episodes ranged from $1.5 \%$ (Taiwan) to $19.0 \%$ (Beirut), with the midpoints at $9.2 \%$ (West Germany) and 9.6\% (Edmonton, Canada)1. The prevalence of mood disorders was found to be $9.5 \%$ in the general population and was the second most common group of mental disorders after anxiety disorders in a national comorbidity survey in USA2. In January 2011 WHO estimates that: More than 150 million people worldwide suffer from depression.3.

Depressive disorder has significant potential morbidity and mortality. Suicide is the second leading cause of death in persons aged 20-35 years and depressive disorder is a major factor in around $50 \%$ of these deaths 4 . The death rate amongst people with a mood disorder may be as high as $15 \%$. It is also associated with high rates of comorbid

*Al-Rashad Training Hospital

**Dept. of Medicine, College of Medicine, University of Baghdad nesif2012@gmail.com

***Dept. of Medicine, College of Medicine, University of Thi-Qar alcohol and substance misuse, and has a considerable social impact on relationships, families, and productivity5. A consistent finding in the literature is the relationship between stressors and the development of depressive symptoms in the college student. In addition, the coping skills of an individual significantly impact his or her response to stress. Individuals experience stress when they are faced with demands that may exceed their ability to cope (Dyson \& Renk, 2006)6. When faced with these stressors, students must utilize coping strategies to manage and effectively adapt to the pressures in their lives. The inability to effectively manage these stressors may lead to chronic levels of high anxiety for college students. Chronic levels of high anxiety have been associated with the development of depressive symptoms in college students (Reed et al., 1996)7. It was found that about a quarter of students $(27.7 \%)$ visited a health student's center of Sultan Qaboos University in Oman scored more than 11 on PHQ98. Unfortunately, many college students who have depression are not getting the help they need. They may not know where to go for help, or they may believe that treatment will not help. Others do not get help because they think their symptoms are just 
part of the typical stress of college, or they worry about being judged if they seek mental health care9. In Iraq data about depression among university students are scarce. This study aims to find out the point prevalence of depressive symptoms in medical students of Baghdad College of Medicine, University of Baghdad and its association with life stressors.

\section{Subjects and Methods:}

A cross sectional study was carried out through March and April 2013 at Baghdad College of Medicine, University of Baghdad. A random sample from 2nd year to 6th year students was asked to fill a self-reporting questionnaire which includes sociodemographic information, Patient Heath Questionnaire 9 (PHQ9)10, 11, Beck Depression Inventory II (BDI-II) 12, and Student stressors questionnaire (scale) 13. First year students were excluded for logistic reasons. Fifty students were chosen randomly from the lists of names of each year. The way of filling the questionnaire was explained to them in groups and they were given one-week period to complete and return the questionnaire. The PHQ-9, which is based on DSMIV criteria, has the potential of being a dual-purpose instrument that, with the same 9 items, can establish depressive disorder diagnoses as well as grade depressive symptom severity. The maximum total score for all 9 items is 27 . We use the cut-off point of 10 to make a diagnosis of depression. The Arabic version of BDI-II is a 21-item self-reported depression-screening tool. Each item is rated on a 4point Likert-type scale ranging from 0-3, with higher scores indicating higher levels of depression. A cutoff point of 17 indicates clinical depression. The stressors scale for college student was used to assess the stress level among students. It contains five groups of stressors; educational stressors (6 questions), psychological stressors (14questions), environmental stressors (6 questions), political stressor (5 questions), and economical stressors (5 questions). The total questions are 36. Each question is scored from one to five with a total score of 180. Data was analyzed by using SPSS version 18 and appropriate tests were used to test the significance.

\section{Results}

Two hundred fifty students (140 females and 110 males) were surveyed. Female to male ratio was 1.27. Their age ranged between $18-45$ years and the mean age was $(22.2 \pm 2.3)$. The majority of students were single $(91.6 \%)$ and $(6.4 \%)$ were engaged. The majority of student describes their economic status as good $(54.8 \%)$ and middle $(34.4 \%)$ while the minority present in two extremity rich $(7.2 \%)$ and economical difficulty $(2.8 \%)$.
Table (1): Socio-demographic characteristics

\begin{tabular}{|c|c|c|c|}
\hline variable & & N0. & percent \\
\hline \multirow{2}{*}{ gender } & male & 110 & 44 \\
\hline & female & 140 & 56 \\
\hline \multirow{4}{*}{$\begin{array}{l}\text { Marital } \\
\text { status }\end{array}$} & Single & 229 & 91.6 \\
\hline & engaged & 16 & 6.4 \\
\hline & married & 3 & 1.2 \\
\hline & divorced & 1 & 0.4 \\
\hline \multirow{2}{*}{$\begin{array}{l}\text { Have } \\
\text { history } \\
\text { chronic } \\
\text { disease }\end{array}$} & yes & 12 & 4.8 \\
\hline & no & 238 & 95.2 \\
\hline \multirow{2}{*}{$\begin{array}{l}\text { Psychiatric } \\
\text { history } \\
\text { (visit } \\
\text { psychiatrist) }\end{array}$} & yes & 12 & 4.8 \\
\hline & no & 238 & 95.2 \\
\hline \multirow{5}{*}{$\begin{array}{l}\text { Misuse of } \\
\text { prescription } \\
\text { drugs }\end{array}$} & never & 188 & 75.2 \\
\hline & rarely & 36 & 14.4 \\
\hline & Some times & 22 & 8.8 \\
\hline & Many times, & 3 & 1.2 \\
\hline & always & 1 & 0.4 \\
\hline
\end{tabular}

Prevalence of clinically significant Depressive symptoms according to PHQ9 Diagnosis:mTwentyeight percent have clinically significant depressive symptoms (may fit to criteria of major depression), $12.4 \%$ have milder form of depressive symptoms (may fit to criteria clinical minor depression / dysthymia) and $59.6 \%$ were subclinical or not meet criteria of depression (table 2). Prevalence of clinically significant depressive symptoms according to BDI II results: Clinically significant depressive symptoms were found among $37.2 \%$ (borderline clinical depression to extremely severe depression) and $62.8 \%$ were subclinical or normal (table 2).

Table (2): Prevalence of depressive symptoms according to PHQ9 and BDI-II

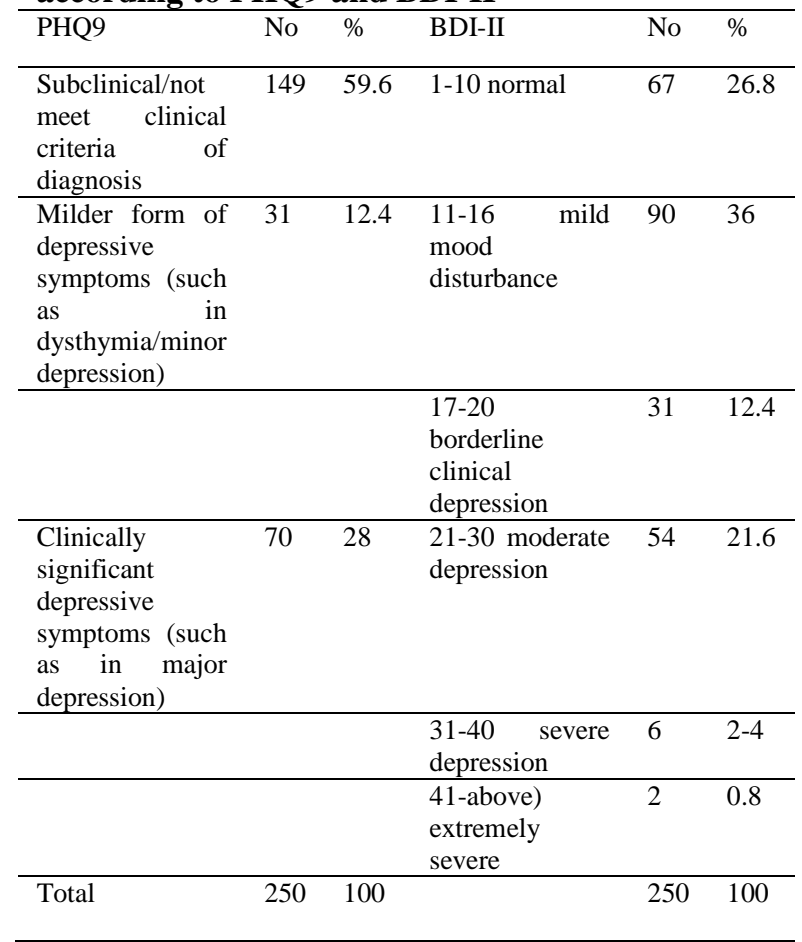


By using regression analysis, the results were compatible in more than $80 \%$ of cases (strongly correlated with $P$ value $=0.000$

Clinically significant depressive symptoms in relation with socio-demographic Data: In this study, clinically significant depressive symptoms were more common among students who, are female $(\mathrm{P}=0.040)$, have economic difficulties $(\mathrm{P}=0,013)$, have chronic disease $(\mathrm{P}=0.005)$, have history of psychiatrist visit $(\mathrm{p}=0.046)$ and, use a nonprescribed drug $(\mathrm{P}=0.004)$. Life stressors: The mean of life stressors scores was 97.98 out of 180 $(\mathrm{SD}=18.68)$. The minimal score obtained by students was 40 out of 180 and maximum score obtained was 151 out of 180 .

Table (3): life stressors score with subcategory score descriptive statistics

$\begin{array}{clllll} & \mathrm{N} & \text { minimum } & \text { maximum } & \text { mean } & \text { SD } \\ & & & & & \\ \text { life stressor score/180 } & 250 & 40 & 151 & 97.98 & 18.682 \\ \text { educational score/30 } & 250 & 6 & 30 & 19.12 & 4.228 \\ \text { psychological score/70 } & 250 & 14 & 61 & 35.06 & 7.698 \\ \text { environment score/30 } & 250 & 6 & 29 & 14.36 & 5.133 \\ \text { political score/30 } & 250 & 6 & 30 & 9.09 & 3.548 \\ \text { economical score/20 } & 250 & 4 & 20 & & 3.278 \\ \text { Valid N (list wise) } & 250 & & & \end{array}$

When the statistical relation between life stressors scores means for each group of PHQ9-BDI II combined diagnosis was tested, it was found that the least mean (92 from 180) was in those who were negative for depression in bothPHQ9 and BDI II tests while highest mean was in the group of positive results $(\mathrm{P}$ value $=0.000)$.
Regarding the subcategory of life stressors, it is found that the relation in their scores means and PHQ-BDI-II combined diagnosis was significant (P value $<0.05$ ) in three areas of stressors (educational stressors, psychological stressors, and environmental stressors) while it was not significant ( $\mathrm{P}$ value> 0.05 ) in two areas of stressors (political stressors and economical stressors).

Table (4): Relation between life stressors scores mean and PHQ9-BDI II combined diagnosis

\begin{tabular}{|c|c|c|c|c|c|c|c|}
\hline & & $\begin{array}{ll}\text { life } & \text { stressor } \\
\text { score } & \\
\end{array}$ & $\begin{array}{l}\text { educational } \\
\text { score } / 30\end{array}$ & $\begin{array}{l}\text { psychological } \\
\text { score } / 70\end{array}$ & $\begin{array}{l}\text { environment } \\
\text { score/30 }\end{array}$ & political score/30 & $\begin{array}{l}\text { economical } \\
\text { score } / 20\end{array}$ \\
\hline & & mean & mean & mean & mean & mean & mean \\
\hline \multirow{4}{*}{$\begin{array}{l}\text { PHQ and } \\
\text { BDI } \\
\text { relation } \\
\text { (combined } \\
\text { Dx) }\end{array}$} & $\begin{array}{l}\text { both subclinical } \\
\text { or negative }\end{array}$ & 92 & 18 & 32 & 13 & 20 & 9 \\
\hline & $\begin{array}{ll}\text { just } & \text { BDI } \\
\text { clinically } & \\
\text { significant } & \\
\end{array}$ & 103 & 20 & 38 & 16 & 20 & 9 \\
\hline & $\begin{array}{l}\text { just } \quad \text { PHQ } \\
\text { clinically } \\
\text { significant }\end{array}$ & 105 & 21 & 37 & 16 & 21 & 10 \\
\hline & $\begin{array}{l}\text { both clinically } \\
\text { significant }\end{array}$ & 104 & 20 & 38 & 16 & 21 & 9 \\
\hline $\mathrm{P}$ value & & .000 & .002 & .000 & .000 & .515 & .189 \\
\hline
\end{tabular}

Relationship between life stressors category and clinical depressive symptom: It is found that there is strong statistical relationship between life stressor category and clinically significant score of PHQ9 ( $\mathrm{P}$ value $=0.000)$, for example, there is only $5 \%$ with symptoms that may fit to major depression diagnosis in low stress group while there is $46.6 \%$ with symptoms that may fit to major depression diagnosis in high stress group as shown in figure 1 .

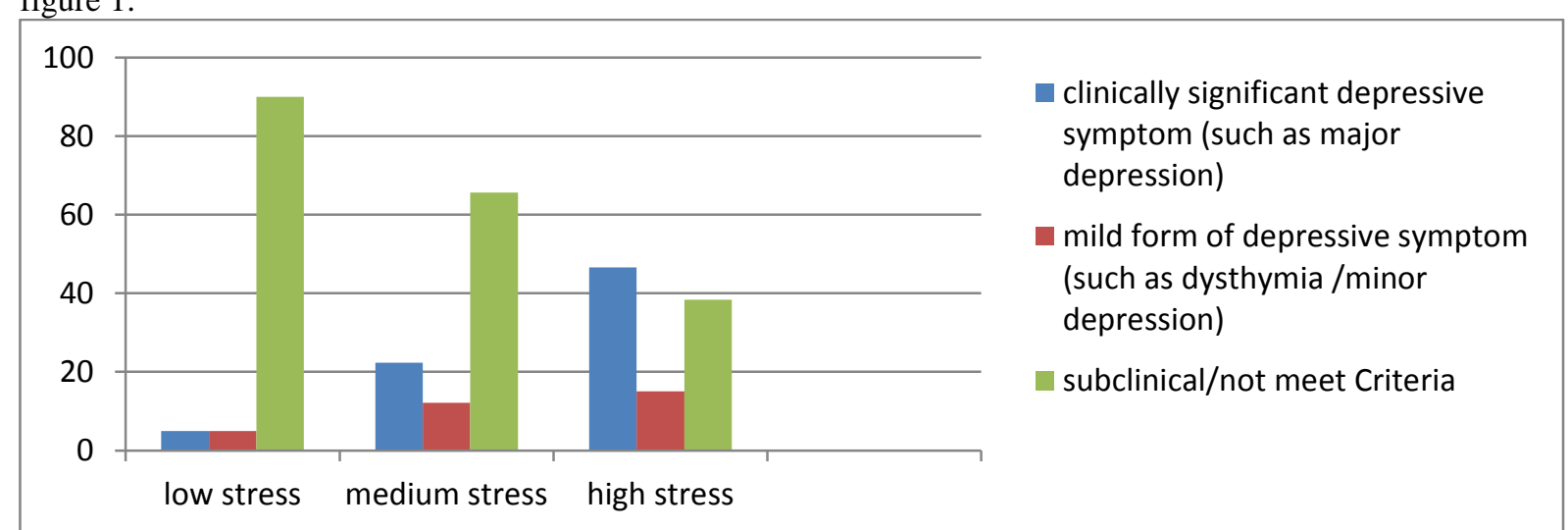

Figure (1): Relation between PHQ9 diagnosis and life stressors category 


\section{Discussion:}

The point prevalence of clinically significant depressive symptoms was $40.4 \%$ according to PHQ9 (28\% with clinically significant symptoms may fit to major depression criteria and $12.4 \%$ with milder form of depressive symptom such as in dysthymia), and $37.2 \%$ according to BDI II $(24.8 \%$ with moderate to extremely severe depression and $12.4 \%$ with borderline clinical depression) and after the use of PHQ9 and BDI-II combined diagnosis and exclude the cases that have different results between the two questionnaires, it is found that $28.8 \%$ of students have clinically significant depressive symptoms. This high prevalence of depressive symptoms may be due to the exposure to a high level of stress and to the younger age. Prevalence of major depressive disorder in 18-29 years old individuals is three folds higher than the prevalence in individuals' age 60 years or older14.This finding is consistent with a study in Lebanon which found that the prevalence of depression among medical students was $27.63 \% 15$. It is also consistent with the findings of similar studies in Oman and Saudi Arabia, which found a prevalence of $(27.7 \%)$ and $(48.2 \%)$ respectively8, 16. In another Saudi study in King Abdul-Aziz University, it is found that $21.8 \%$ \& $14.7 \%$ had borderline \& morbid depression, respectively 17 . The difference in prevalence is likely to be related to the different screening tools used in the Saudi study (Hospital Anxiety and Depression Scale (HADS). In a study among medical students in India which used BDI-II as a screening tool, about half $(49.1 \%)$ of the students had symptoms of depression ( $60 \%$ of females and $42 \%$ of males). In this study, they used the same cut-off point that we used, but the results were higher which may indicate a higher prevalence of depression in Indian students. This can be attributed to cultural differences18. In a study among students of Midwestern Public University in the United States, $17 \%$ of them screened positive for depressive symptoms, including $9 \%$ who met criteria for major depression19. This result is lower than this study and other regional studies, which may be due to difference in the culture and the level of stressors. The screening tools used in this study, although have good sensitivity and specificity, are subjective and rating of symptoms by students might not be accurate. Depressive symptoms can associate many mental disorders like anxiety, stress-related, and adjustment disorders, which cannot be excluded by these tools. Regarding the level of stress; a minor group $(8 \%)$ of students have low stress, the major group $(62.8 \%)$ of students have moderate stress, and $29.2 \%$ of students have high stress. This result is consistent with a study in Government Medical College in Surat, India, which revealed that 3.12\% of the undergraduate medical students reported having no stressor experience, $55.6 \%$ reported mild to moderate stressor experience and $41.2 \%$ with severe stressor experience20. The level of stress reported in this study was lower than that reported by a similar study in the Open University of Al-
Quds. In this study, $17 \%$ of students have low stress, $37 \%$ of students have moderate stress, and the major group $(46 \%)$ has high stress 13 . It is found that the presence of clinically significant depressive symptoms is proportionate with level of stress and it was found that only $10 \%$ from those with low stress have clinical depressive symptoms that were revealed by both PHQ9-BDI II, while this ratio increased to $23.6 \%$ in the moderate stress group and to $45.2 \%$ in the high stress group. This finding is compatible with many studies in the world 4,14 . Students who described their status with economical difficulty are more likely to have clinically significant depressive symptoms in both PHQ-9 and BDI-II (100\%) than other group followed by those who described their economic status as rich (44.4\%), and those who described their economic status as middle $33.7 \%$ and the least one who described themselves as having good economic status (20.4\%).This U-shaped relationship might be explained by the presence of another kind of difficulty for rich students which might be related to the parental priority to cover financial needs rather than emotional needs for their children. This result is consistent with a Saudi study, which showed that Students with insufficient income or who perceived their income as 'not sufficient' had also a higher rate of depression than others 17. It is also consistent with a study in United States, which showed that economic strain as difficulty paying bills is significantly related to depressive symptoms in early adulthood21. Those who have chronic disease were more likely to have clinical depressive symptoms in both PHQ-9 and BDI-II. This result seems consistent with literature that revealed that mood disorders, particularly depression, accompany a range of medical problems. Those who misuse a nonprescribed drug were more likely to have a diagnosis of depression in both PHQ-9 and BDI-II than others were. This result is consistent with American studies, which revealed that more college students diagnosed with depression have used alcohol, marijuana, cocaine, or amphetamines than have their peers who have no depression22. This study has many limitations like the small sample, and the use of screening tools that cannot exclude depressive symptoms due to other mental disorders. In spite of that, it raises the possibility of the presence of a high level of mood problems among medical school students due to high levels of stress. Students need to be aware of these symptoms, which might lead to significant personal suffering and negative effect on their academic performance. Interventions to educate students about depression might be useful. The deanery might be advised to look at the educational stressors of students to minimize them in order to decrease the prevalence of depressive symptoms. Future studies need to include larger samples from many medical schools in Iraq, and to use screening/diagnostic tools that can investigate for the whole range of mental disorders that present with depressive and anxiety symptoms. 


\section{Conclusion:}

This study showed a high prevalence of clinically significant depressive symptoms in medical college students. High stress level is associated with the presence of clinically significant depressive symptoms. Educational, psychological and environmental stressors are the main types of stress.

\section{Author's contribution:}

Firas Ali Azeez Al-Kadhimi: Study design, collection of data, and data analysis

Nesif Al-Hemiary: Study design, supervision of data collection, editing the manuscript.

Ahmed Hassan: Edition of the manuscript

\section{References:}

1. Ronald C., KesslerI, and Evelyn J.:The epidemiology of depression across cultures. Annu Rev Public Health. 2013; 34: 119-138.

2. Kessler RC1, Chiu WT, Demler O, Merikangas $K R$, Walters EE..Prevalence, severity, and comorbidity of 12-month DSM-IV disorders in the National Comorbidity Survey Replication.Arch Gen Psychiatry. 2005 Jun;62(6):617-27

3. World Health Organization: mhGAP Newsletter, Mental Health Gap Action Program. Department of Mental Health and Substance Abuse (MSD), January 2011.

4. Sadock, Benjamin J.; Sadock, Virginia A.; Ruiz, Pedro, Kaplan \&Sadock's Comprehensive Textbook of Psychiatry, 9th Edition, Lippincott Williams \& Wilkins; 2009.

5. Semple D, Smyth R. Oxford Handbook of Psychiatry, 2nd Edition. Oxford University Press; 2009.

6. Dyson, R., \&Renk, K. Freshmen adaptation to university life: Depressive symptoms, stress, and coping. Journal of Clinical Psychology; 2006, 62(10), 1231-1244.

7. Reed, M. K., McLeod, S., Randall, Y., \& Walker,

B. Depressive symptoms in African-American Women. Journal of Multicultural Counseling and Development; 1996, 24(1), 6-14.

8. Al-Busaidi Z, Bhargava K, Al-Ismaily A. et al. Prevalence of Depressive Symptoms among University Students in Oman. Oman Medical Journal; 2011. Vol. 26, No. 4: 235-239.

9. Michael D, Hueisman T, Gerard C, Gilligan T, Gustafson M. Depression Among College Students: Trends in Prevalence and Treatment Seeking. Appalachian State University, Counseling and Clinical Psychology Journal, 2006.

10. Macarthur John D. \& Catherine T. Depression management tool kit. The Macarthur initiative on depression and primary care; 2009. Available from: http://www.sprc.org/for-providers/primary-careresources
11. Spitzer R. L., Williams J. B., Kroenke K. et al. Patient health questionnaire 9 (PHQ9) Arabic version. PRIME-MD® is a trademark of Pfizer Inc.; 1999. Available from:http://www.refugeehealth.ca/sites/default/files/ PHQ9\%20-\%20Arabic_1.pdf

12. Muamria B. testing for Beck depression inventory II on samples of male and female in Algeria. Arab psynet e. Journal: $N^{\circ} 25-26$ - Winter \& Spring 2010.

13. Barakat Z. Sources of stressor as perceived by students of Al-Quds Open University according to gender variance (in Arabic). Al-Quds Open University, Tol-Karem educational region; 2007.

14. American Psychiatric Association: Diagnostic and Statistical manual of mental disorder, fifth edition. Arlington, VA, American Psychiatric Association, 2013.

15. Mehanna Z, Richa S. Prevalence of anxiety and depressive disorders in medical students. Transversal. Encephale, 2006. 32:976-82.

16. Al-Faris E. A, Irfan F, Van Der Vleuten et al. The prevalence and correlates of depressive symptoms from an Arabian setting: A wake up call. Medical Teacher; 2012; 34: 32-36.

17. Ibrahim N, Al - Kharboush D, El - Khatiblamis , Al - Habib A. , Asali D. Prevalence and Predictors of Anxiety and Depression among Female Medical Students in King Abdulaziz University, Jeddah, Saudi Arabia. Iranian Journal for Public Health, Vol. 42, No.7, July 2013, pp.726-736.

18. Singh A, Lal A, Shekhar. Prevalence of Depression among Medical Students of a Private Medical College in India. Online Journal of Health and Allied Sciences. Volume 9, Issue 4; Oct-Dec 2010.

19. Eisenberg, D., Gollust, S.E., Golberstein, E., \& Hefner, J.L. Prevalence and correlates of depression, anxiety, and suicidality among university students. Journal of Orthopsychiatry, 2007. 77(4), 534-542.

20. Solanky P, Desai B, Kavishwar A, Kantharia S. L. Study of psychological stress among undergraduate medical students of government medical college, surat. International Journal of Medical Science and Public Health; 2012. Vol 1, Issue 2.

21. Miech R. A, Shanahan M. J, Elder G. $H$. Socioeconomic Status and Depression in Life Course Perspective. Center for Demography and Ecology / University of Wisconsin-Madison, CDE Working Paper No. 98-24

22. Ross V. Depression, Anxiety, and Alcohol or Other Drug Use among College Students. National College Health Assessment. American College Health Association. October 2000. 